Nepal Journal of Multidisciplinary Research (NJMR)

Vol. 3, No. 1, June 2020. Pages. 7-14

ISSN: 2645-8470 (Print), ISSN: 2705-4691 (Online)

DOI: https://doi.org/10.3126/nimr.v3i1.30214

\title{
Predatory publishing: A threat to the credibility of science
}

\author{
Jiban Shrestha ${ }^{1}$, Subash Subedi ${ }^{2}$ and Krishna Prasad Timsina ${ }^{3}$ \\ ${ }^{1}$ Nepal Agricultural Research Council (NARC), \\ Agriculture Botany Division, Khumaltar, Lalitpur, Nepal \\ ORCID: https://orcid.org/0000-0002-3755-8812 \\ Email: jibshrestha@gmail.com \\ ${ }^{2}$ National Maize Research Program, NARC, \\ Rampur, Chitwan, Nepal \\ ORCID: https://orcid.org/0000-0003-3739-1773 \\ Email: subedi.subash1@gmail.com \\ ${ }^{3}$ Socio-economic and Agricultural Research Policy Division, \\ NARC, Khumaltar, Lalitpur, Nepal \\ ORCID: https://orcid.org/0000-0003-4005-7039 \\ Email: krishnatimsina2000@gmail.com
}

Received: May 20, 2020; Revised \& Accepted: July 11, 2020; Published: July 19, 2020

(C) Copyright: Shrestha et al. (2020).

(c) (1) (3)

This work is licensed under a Creative Commons Attribution-Non Commercial $\underline{4.0}$ International License.

\begin{abstract}
Predatory journals pose a global threat to science. Young scientists and scholars are easy victims of the predatory publications. Predatory publications reduce the accuracy, reliability, and validity of the scientific works published. The predatory publications are worthless, just a waste of time, resources, money, and efforts. Predatory publications undermine the value of legitimate publications. In order to discourage predatory publications, educational and research institutions should set the rules for publication in the journals that must be indexed in web of science,
\end{abstract}




\section{Nepal Journal of Multidisciplinary Research (NJMR) \\ Vol. 3, No. 1, June 2020. Pages. 7-14 \\ ISSN: 2645-8470 (Print), ISSN: 2705-4691 (Online) \\ DOI: https://doi.org/10.3126/nimr.v3i1.30214}

Journal Citation Reports (JCR, Clarivate Analytics, formerly Thomson-Reuters) or other famous scientific databases such as Scopus, DOAJ, PubMed, and MEDLINE. Citation of articles from predatory journals should be discouraged. The students, academics, and researchers should be careful to avoid predatory publications to maintain their credentials.

Keywords: Citation, journals, predatory publishing, threat of publication.

\section{Introduction}

Predatory publishing is an exploitative fraudulent open-access publishing model (Sarfraz et al., 2020). Jeffrey Beall, an associate professor at the University of Colorado Denver and a librarian at Auraria Library, coined the term "predatory journals" to describe pseudo-journals (Ferris and Winker, 2017; Cobey et al., 2018; Laine and winker, 2017). Cortegiani et al. (2019) define predatory publishing as an exploitative fraudulent open-access publishing model that operates under the false pretense of legitimate publishing without actually offering legitimate editorial services. Beall compiled yearly lists of possible, potential, or probably predatory open access journals from 2011 to 2017. Beall also listed concrete criteria that identified such journals with an updated index that continues to locate the pseudo-journals. Two additional lists, hijacked journals, and misleading metrics were added in 2015 (Laine and Winker, 2017). Hijacked journals refer to bogus websites that resemble legitimate journals to solicit submissions and collecting publication fees from authors who are misled to believe that the journal is legitimate. The publication in fraudulent journals is growing day by day. There are 1338 predatory journals and 1198 predatory publishers reported in 2019 (https://predatoryjournals.com/journals/). The number of such articles increased rapidly from 53,000 in 2010 to approximately 420,000 in 2014, published by approximately 8,000 active journals (Shen and Bjork, 2015). The number of fake conferences or fake papers published at conferences is also growing day by day. As a test, Bohanon submitted fake scientific papers to 304 selected journals, 157 of which accepted them (Bohannon, 2013). Bohanon found that 85 fake papers were accepted at 24 different conferences in 2013 (Bohannon, 2015). The trend of predatory publishing is growing rapidly as submissions are done by fellow novice writers and writers who are unfamiliar with the journals' poor quality. Another reason may be that students need one or two papers that are published as compulsory criteria to submit a dissertation and don't have enough time to publish them in good journals so that they can easily choose to be published in predatory online journals.

Predatory journals are a global challenge now. By publishing in predatory journals, scientists have quickly made their work useless, illegal, and stigmatized. Predatory publishers accept articles for publication - including author fees - without carrying out the promised quality checks on issues such as plagiarism or ethical approval. Predatory publishers usually take a quick phase 


\section{Nepal Journal of Multidisciplinary Research (NJMR) \\ Vol. 3, No. 1, June 2020. Pages. 7-14 \\ ISSN: 2645-8470 (Print), ISSN: 2705-4691 (Online) \\ DOI: https://doi.org/10.3126/njmr.v3i1.30214}

without assessment, these publishers incorrectly reference or exaggerate the reputation of editorial staffs and trigger inconvenience and falsification of affiliation to institutions and database lists. Carroll (2015) recommends that if a guaranteed acceptance offer or a quick review process is made, it could be fraudulent and predatory. Olson (2017) believes that predatory journals do not have identifiable information about publishers, contact information, and editorial board members. Predatory publishing puts the writers in a lot of trouble. Predatory publishers cannot guarantee the continued availability of articles, because they disappear a few years after all articles have been made accessible from online sources. Predatory journals usually do not practice the peer-review process, which leads to poor quality of published articles. Predatory publication worsens the image of authors who are suffering from the abandonment of employment agencies or donor organizations.

It is therefore an immediate need to build an understanding of unethical publications at academic institutions and universities. With regard to ongoing threats, it is urgent to warn both authors and publishers of the relevance and reliability of the published work.

\section{Methodology}

Relevant literatures from 2012 to 2020 were collected from journal articles, website materials and news papers on ways to recognize predatory journals, harmful effects of predatory publishing, ways to recognize legitimate journals and ways to discourage predatory publishing. Authors' knowledge in predatory publishing are also internalized in the paper. Finally, information collected from different sources were analyzed and presented in this paper.

\section{How to recognize the predatory journal}

Predatory journals are characterized by spam messages used to collect manuscripts. In such journals, there is a lack of peer or low-quality review processes, periods of rapid transition from presentation to publication, fake impact factors, the introduction of scientists into the editorial board without approval of academics, and not included in a database for dissemination (Beaubien and Eckard, 2014; Berger and Cirasella, 2015; Shen and Bjork, 2015; Shrestha et al. 2019a: Shrestha et al., 2019 b). Predatory publishers exploit a new publishing model by claiming to be legitimate open-access operation. Online predatory publishers take advantage of the Gold Open Access model (O'Donnell, 2020). Some predatory publishers advertise that they are included in well-known databases like Web of Science or Scopus and DOAJ when they are not (O'Donnell, 2020). Denial (2016) pointed out that the predatory publisher has an extremely vague scope of journal or scope is not mentioned. Statements about journal scope are absent or extremely vague. 


\section{Nepal Journal of Multidisciplinary Research (NJMR) \\ Vol. 3, No. 1, June 2020. Pages. 7-14 \\ ISSN: 2645-8470 (Print), ISSN: 2705-4691 (Online) \\ DOI: https://doi.org/10.3126/njmr.v3i1.30214}

The same authors publish more than one articles in the same issue of a journal. JCR was the only published source of impact factor (IF) journals before the introduction of the SJR indicator from Scopus data. The SJR indicator is designed to classify scientific journals based on citation weighting schemes and journal quality indicators used by Scopus to assess quality (Mahmood and Almas, 2016). The SJR allows not only citation counts but also works as an indicator of the importance and influence of citing journals (Khurshid, 2014). SJR also overcomes many other biases which include geography, language, size of journal collections, the quote itself, and the time frame (Mahmood and Almas, 2016). Another important factor for verifying the quality of a journal is the Journal Rating Index (JRK).

\section{Harmful effects of predatory publication}

Predatory journals have negative effects on scientific integrity. They lead to spreading junk science (Dadkhah et al., 2017) and can decrease the academic ranking of countries (Forero et al., 2018). Some predatory online publications exist for very short periods and are rarely cited in journals indexed by reliable databases (Beall and DuBois, 2016). If your work is published by a predatory journal, it could disappear off their web site at any time. Many predatory publishers will claim that their journals are indexed in major databases such as PubMed or Scopus when, in fact, they aren't.But, without being indexed in scientific databases, it is hard to find, use, and cite work overtime. Predatory publishing has created a significant amount of published literature, which has been called science but has not passed proper peer review. For many readers, reporters, and the public, the distinction between authentic and junk science is not easily distinguished, but these publications are easily accessible to everyone (Beall and DuBois, 2016). Misinterpretation or false and fake results published in predatory journals harm human health, wealth, and society. Predatory publishing is also harmful to libraries,

\section{How to recognize the legitimate journal}

Publication in genuine journals facilitates researchers for international research cooperation among institutions, an international grant for travel research, and an international scholarship (Samuel, 2018). Many potential authors and researchers are unaware of the problem that many predatory journals are indistinguishable from legitimate journals (Xia et al., 2015). Authors must search for authentic databases such as Scopus, PubMed, MEDLINE, and Thomson Reuters Web of Science to choose the actual publishers to publish. Journal Citation Journal (JCR) indicators and SCImago Journals Rankings (SJR) are two best ways to find good journals to publish. .JCR is an option used to display the actual journal's actual impact factor (IF) before Scopus data 


\section{Nepal Journal of Multidisciplinary Research (NJMR) \\ Vol. 3, No. 1, June 2020. Pages. 7-14 \\ ISSN: 2645-8470 (Print), ISSN: 2705-4691 (Online) \\ DOI: https://doi.org/10.3126/nimr.v3i1.30214}

comes out. Quality journals appear in the Scopus database (Mahmood and Almas, 2016). Elliott (2012) mentioned that the COPE code of conduct should act as a guideline for determining whether it is a genuine or a false article. The criteria of reputable journals/publishers are publisher is a member of Open Access Scholarly Publishers Association (OASPA), journal scope is well defined and clearly stated on the journal's website, editors and the editorial board consists of recognized experts in the field, the peer-review process is rigorous and clearly explained on the website. To be a good journal it must have articles with particular Digital Object Identifiers (DOIs) provided by crossref (https://www.crossref.org), International Standard Serial Number (ISSN), Copyright, renowned editorial team, and also should be a member of an Open Access Scholarly Publishers Association (OASPA), Directory of Open Access Journals (DOAJ). It should also have clear usage rights e.g. Creative Commons License (CC by License). Contact information is provided and available, publishing schedule and publication frequency is clearly stated, the fee structure is clearly explained and easy to find on website, and the journal is indexed in subject databases or indexes. The Think. Check. Submit. website (https://thinkchecksubmit.org) provides helpful guidance. Besides, the Committee on Publication Ethics (COPE), Directory of Open Access Journals (DOAJ), the International Committee of Medical Journal Editors (ICMJE), the Society for Scholarly Publishing (SSP), Open Access Scholarly Publishers Association (OASPA), and World Association of Medical Editors (WAME) and the Association of Learned and Professional Society Publishers (ALPSP) created the Principles of Transparency and Best Practice in Scholarly Publishing. Those criteria help assess a journal.

Upto July 2020 in Nepal there are 180 journals listed on NepJOL (https://www.nepjol.info/). Among them only 7 journals are indexed in SJR (Scimago Journal Rank), 5 journals are indexed in Pubmed (https://epomedicine.com/blog/nepalese-medicaljournals/ ). The majority of these journals are not indexed in DOAJ, Scopus and Pubmed because they are either new in origin or still not meeting the qualities for indexing to them. Only one joural was listed in Beall's predatory lists, others are not listed in predatory lists. The journals listed in NepJOL may not be predatory but may of poor qualities. Journal Publishing Practices and Standards (JPPS) framework was established by INASP to jugde the qualities of Nepalese journals. The publishers should be responsible for qualities of journal articles.

\section{How to discourage predatory publishing}

Predatory journals have rapidly increased their publication volumes from 2010 to date and will increase more in the future. To discourage predatory publications, authors should also consult the Committee on Publication Ethics (COPE), which is available to promote ethical and moral publishing behavior (Yucha, 2015). However, keep in mind that some predatory publishers may 


\section{Nepal Journal of Multidisciplinary Research (NJMR) \\ Vol. 3, No. 1, June 2020. Pages. 7-14 \\ ISSN: 2645-8470 (Print), ISSN: 2705-4691 (Online) \\ DOI: https://doi.org/10.3126/nimr.v3i1.30214}

incorrectly place the COPE logo on your website, even if you are not a member of the organization (Roberts, 2016). Other indexing services that list well-reputed publications are the International Association of Scientific, Technical, and Medical Publishers (STM) and the Open Access Scholarly Publishers Association (OASPA) (Shahriari et al., 2016). Some journals claim that they are registered in DOAJ and keep information of DOAJ on their website but they are not registered in DOAJ. Publication of articles in Scopus indexed journals should be made as criteria of publication. The authors should visit the title list on the Scopus. Scholarly databases such as Scopus, PubMed, MEDLINE, and Thomson Reuters Web of Science need to raise the bar for acceptance, eliminating journals and publishers that use flawed peer-review practices. Universities and colleges should stop using the number of published articles as a measure of academic performance. Publications in predatory journals should not count towards employment or promotion. Researchers should avoid citing papers published in predatory journals. Institutions or universities are required to publish in journals that are listed in Web of Science's Journal Citation Reports (JCR, Clarivate Analytics, formerly Thomson-Reuters), Scopus, and DOAJ. To counteract such predatory publication, some national funding bodies and universities have incorporated the list of predatory journals into their blacklist of journals and publishers.

\section{Conclusion}

Predatory journals have been growing worldwide in the recent era, with no or very low quality peer-review process. Predatory journals are one of the biggest threats to the reputation of academic publishing. Predatory publishing not only harms or degrades academic reputations but also wastes time, money, resources, and efforts. Such publication is worthless. Therefore, researchers and scholars need to be aware of predatory journals before submitting their manuscripts. The academic and research institutions need to revise their publishing requirements in order to accept high-quality publications and prevent fraudulent publishing.

\section{Conflict of interests}

The authors had not declared any conflict of interest.

\section{References}

Beall, J., \& DuBois, J.M. (2016). Scholars beware. https://www.apa.org/monitor/2016/04/scholars

Beaubien, S., \& Eckard, M. (2014). Addressing faculty publishing concerns with open access journal quality indicators. Journal of Librarianship and Scholarly Communication, 2(2), p.eP1133. DOI: http://doi.org/10.7710/2162-3309.1133.

Berger, M., \& Cirasella, J. (2015). Beyond Beall's list: better understanding predatory publishers. College and Research Libraries News, 76(3), 132-135. 
Nepal Journal of Multidisciplinary Research (NJMR)

Vol. 3, No. 1, June 2020. Pages. 7-14

ISSN: 2645-8470 (Print), ISSN: 2705-4691 (Online)

DOI: https://doi.org/10.3126/njmr.v3i1.30214

Bohannon, J. (2013). Who's afraid of peer review. Science, 342(6154), 60-65. DOI:

10.1126/science.342.6154.60.

Bohannon, J. (2015). Hoax-detecting software spots fake papers. Science, 348(6230), 18-19.

DOI: $10.1126 /$ science.348.6230.18.

Carroll, V.S. (2015). Watch out for the wolves: Predatory publishing. Journal of Neuroscience Nursing, 47, 1-2. DOI: 10.1097/JNN.0000000000000126

Cobey, K.D., Lalu, M.M., Skidmore, B., Ahmadzai, N., Grudniewicz, A., \& Moher, D. (2018). What is a predatory journal? A scoping review. F1000Research, 7,1001. DOI: 10.12688/f1000research.15256.2.

Cortegiani, A., Longhini, F., Sanfilippo, F., Raineri, S.M., Gregoretti, C., \& Giarratano, A. (2019).Predatory open-access publishing in anesthesiology. Anesthesia and Analgesia, 128(1), 182-187

Dadkhah, M., Lagzian, M., \& Borchardt, G. (2017). Questionable papers in citation databases as an issue for literature review. Journal of Cell Communication and Signaling, 11, 181-185. DOI: https://doi.org/10.1007/s12079-016-0370-6

Denial, A. (2016). Editorial. Beware of Predatory Publishing. Optometric Education, 42(1), https://journal.opted.org/article/beware-of-predatory-publishing/

Elliott, C. (2012). On predatory publishers: A Q and A with Jeffrey Beall. https://www.chronicle.com/blogs/brainstorm/on-predatory-publishers-a-qa-withjeffreybeall/47667

Ferris, L.E., \& Winker, M.A. (2017). Ethical issues in publishing in predatory journals. Biochem Medica (Zagreb), 27(2), 279-284. DOI: 10.11613/BM.2017.030.

Khurshid, Z. (2014). Measuring the quality of contributions of Saudi authors to LIS journals using Journal Impact Factor (JIF), SCImago Journal Rank (SJR), and Google Scholar Metrics (GSM). The Serials Librarian, 67, 81-98. DOI: 10.1080/0361526X.2014.909755

Laine, C., \& Winker, M.A.(2017). Identifying predatory or pseudo-journals. Biochem Medica (Zagreb), 27(2), 285-291. DOI: 10.11613/BM.2017.031.

Mahmood, K., \& Almas, K. (2016). SCImago Journal Rank Indicator: A Viable Alternative to Journal Impact Factor for Dental Journals. Libres, 26 (2), 144-151.

O'Donnell, M. N. (2020). Understanding Predatory Publishers. What is a predatory publisher?. https://instr.iastate.libguides.com/predatory.

Olson, C.A. (2017) Caveat scholar: On the growth of predatory publishing. Journal of Continuing Education in the Health Professions, 37, 1-2.

Samuel, A.J. (2018).An Indian physiotherapist's suggestions to keep out of fake journals. Physiother . Journal of Indian Association of Physiotherapists, 12, 43-45. DOI: 10.4103/PJIAP.PJIAP_32_17

Sarfraz, Z., Sarfraz, A., Anwer, A., Nadeem, Z., Bano, S., \& Tareen, S. (2020). Predatory Journals: A Literature Review. Pakistan Journal of Surgery and Medicine, 1(1), 42-51. 


\section{Nepal Journal of Multidisciplinary Research (NJMR) \\ Vol. 3, No. 1, June 2020. Pages. 7-14 \\ ISSN: 2645-8470 (Print), ISSN: 2705-4691 (Online) \\ DOI: https://doi.org/10.3126/njmr.v3i1.30214}

Shahriari, N., Grant-Kels, J.M., \& Payette, M.J. (2016). Predatory journals: How to recognize and avoid the threat of involvement with these unethical publishers. Journal of the American Academy of Dermatology, 75, 658-659.

Shen, C., \& Bjork, B. (2015). Predatory open access: a longitudinal study of article volumes and market characteristics. BMC Medicine, 1(13), 230. DOI: 10.1186/s12916-015-0469-2.

Shrestha, J., Subedi, S., Shokati, B., \& Chaudhary, A. (2018b). Predatory Journals: A Threat to Scholarly Publishing. Journal of Education and Research, 8(1), 89-101. https://doi.org/10.3126/jer.v8i1.25482.

Shrestha, J., Subedi, S., Timsina, K., \& Tripathi, M. (2018a). Risk of publication in worthless journals. Journal of Agriculture and Natural Resources, 1(1), 1-5. https://doi.org/10.3126/janr.v1i1.22217

Xia, J., Harmon, J.L., Connolly, K.G., Donnelly, R.M., Anderson, M.R., \& Howard, H.A. (2015). Who publishes in "predatory" journals?. Journal of the Association for Information Science and Technology, 66(7), 1406-17.

Yucha, C. (2015). Predatory publishing: What authors, reviewers, and editors need to know. Biological Research for Nursing, 17, 5-7. DOI: 10.1177/1099800414563378 